\title{
Elaboração de projetos político-pedagógicos: reflexões acerca da atuação do psicólogo na escola
}

\author{
Aline Wanderer \\ Regina Lucia Sucupira Pedroza
}

\begin{abstract}
Resumo
Este trabalho discute a atuação do psicólogo escolar no incentivo à elaboração do Projeto-Político-Pedagógico pela comunidade escolar. Aborda temas como política, relações de dominação/hierarquização escolares, formação/atuação do psicólogo escolar e exercício da autonomia. Abdicando da autoridade de especialista servindo à normatização, o psicólogo pode questionar relações de hierarquização escolares, bem como sensibilizar quanto à ideia de que a identidade da escola é historicamente construída e sua realidade é modificável pela ação coletiva da comunidade. Atuouse numa escola pública de Ensino Fundamental, séries iniciais, de Brasília-DF, utilizando a observação participante em reuniões semanais com a equipe pedagógica e pensando-se a postura do psicólogo como mediador. O Projeto-Político-Pedagógico é importante mecanismo de trabalho coletivo, permitindo a constituição da identidade da escola, de posicionamentos políticos e diretrizes de trabalho coerentes com cada realidade. Enfatizou-se a consolidação de um processo de reconhecimento da possibilidade de autonomia na construção do Projeto-Político-Pedagógico pela equipe pedagógica.
\end{abstract}

Palavras-chave: Psicologia escolar, projeto político pedagógico, atuação do psicólogo.

\section{Elaboration of pedagogic political projects: reflections on the work of the psychologist in school}

\begin{abstract}
In this paper we discuss the performance of the school psychologist in encouraging the school community to elaborate the Pedagogic Political Project. Topics such as politics, school-domination/hierarchy relationships, training / performance of the school psychologist and exercise of autonomy are covered. When the School Psychologist abdicates his or her authority, as an expert in the area, he or she can question the school-hierarchy, as well as persuade others to the idea that a school identity is historically constructed and that its reality is modifiable by the collective action of the community. The study was developed in the initial grades of a public elementary school of Brasilia - DF, by utilizing the participant observation in weekly meetings with the pedagogical team and by thinking about the psychologist's attitude as a mediator. The Pedagogic Political Project is an important mechanism of collective work, which permits the constitution of a school identity, of political positions and work policies which may be coherent to each reality. We highlight the consolidation of recognition of a possible autonomy in the construction of the Pedagogic Political Project by the school community.

Keywords: School psychology, project pedagogical politician, psychologist performance.
\end{abstract}

\section{Elaboración de proyectos político-pedagógicos: reflexiones acerca de la actuación del psicólogo en la escuela}

\begin{abstract}
Resumen
Este trabajo discute la actuación del Psicólogo Escolar en el estímulo a la elaboración del Proyecto Político-Pedagógico por la comunidad escolar. Aborda temas como política, relaciones de dominación/jerarquización escolares, formación/actuación del psicólogo escolar y ejercicio de la autonomía. Abdicando de la autoridad de especialista al servicio de la normalización, el Psicólogo puede cuestionar relaciones de jerarquización escolares, así como también sensibilizar con respecto a la idea de que la identidad de la escuela es históricamente construida y su realidad es modificable por la acción colectiva de la comunidad. El trabajo se realizó en una escuela pública de Enseñanza Primaria, grados iniciales, de Brasilia-DF, utilizando la observación participante en reuniones semanales con el equipo pedagógico y pensando la postura del psicólogo como mediador. El Proyecto Político-Pedagógico es importante mecanismo de trabajo colectivo, permitiendo la constitución de la identidad de la escuela, de posicionamientos políticos y directrices de trabajo coherentes con cada realidad. Se enfatizó la consolidación de un proceso de reconocimiento de la posibilidad de autonomía en la construcción del Proyecto Político-Pedagógico por el equipo pedagógico.
\end{abstract}

Palabras clave: Psicología escolar, proyecto político pedagógico, actuación del psicólogo.

Revista Semestral da Associação Brasileira de Psicologia Escolar e Educacional, SP. Volume 14, Número 1, Janeiro/Junho de 2010: 121-129. 


\section{Introdução}

O presente trabalho discute a possibilidade de atuação do psicólogo escolar no incentivo e colaboração à elaboração do Projeto Político Pedagógico (PPP) pela Comunidade escolar, a partir de uma pesquisa participante. Para tal, reflete acerca de questões como política, relações de dominação e hierarquização escolares, formação e atuação do psicólogo escolar e exercício da autonomia.

Com base nas ideias propostas por Bobbio, Matteucci e Pasquino (1992), observa-se que o conceito de política pode trazer em si uma relação de força, em que um grupo assume a responsabilidade pelos interesses de uma coletividade, sendo que esta, por sua vez, abdica da exigência desses interesses por sua própria força, delegando-a ao grupo dominante.

Com relação à atuação do psicólogo, tal força manifesta-se, pretensamente, na autoridade do especialista, que diagnostica e trata, possui um conhecimento "neutramente" produzido e pode servir-se dele para "ajudar" os indivíduos a se ajustarem ao sistema normatizador. A partir das concepções de Chauí (1994), Patto (2005) e Freire (2001), surge a seguinte reflexão: até que ponto a ação do psicólogo não vem, constantemente, servindo e fortalecendo as ideologias capitalistas e burguesas da contemporaneidade? A ideologia, segundo Chauí (1994), é ideário histórico, social e político que oculta a realidade como forma de assegurar e manter a desigualdade social, bem como as relações de dominação econômica e política. Esse ocultamento ocorre quando as ideias passam a ser consideradas como explicações e justificações da realidade, e não como frutos do contexto histórico, político e social do qual surgem. É consequência da assimilação da ideologia que ela passe a se introjetar nas diversas instituições que compõem a sociedade, inclusive na escola. A educação, considerada como uma das mais importantes portas de entrada dos indivíduos nos valores sociais predominantes em dado momento histórico, é um dos principais instrumentos para a legitimação e perpetuação das ideologias que justificam relações de poder e exploração.

Nesse sentido, é interessante observar o quanto a formação do psicólogo carrega em si a difusão das lacunas legitimadoras da ideologia, tornando-o profissional que atua a serviço da normalização e do que Chauí (1994) denomina de ideologia da competência. Isso porque sua formação ainda vem profundamente impregnada das noções da Ciência Positivista, que teoricamente produz um conhecimento que retrata uma realidade pronta, estática e a-histórica. Assim, a partir de uma formação que mais parece um treinamento ou informação, surgem profissionais reprodutores de conhecimentos que, por meio deles, julgam-se capazes de compreender e manipular o real, ajustando os indivíduos ao que é aceito como "normal", "esperado", "correto".

Para a superação de tal modelo, seria necessária a formação de indivíduos crítica e politicamente conscientes, capazes de se engajar no movimento de denúncia e anúncio proposto por Freire (2001). Esse movimento caracterizase por denúncias das realidades sociais de exploração e dominação e anúncios de projetos concretos e viáveis de ação apoiados em um corpo teórico e em um projeto político. Permite concretizar sonhos possíveis coletivos, tendo discernimento suficiente para integrar eticamente os sonhos individuais em um único compromisso ético-social.

É com essa formação que o psicólogo poderá ter condições de se conscientizar e exercer seu papel político na escola, questionando as posições de autoridade nas relações exercidas nesse contexto. Com isso, promoveria reflexões junto à comunidade a fim de conscientizá-la sobre como as pessoas participam da lógica de manutenção da opressão, contrária à democratização, por meio de disposições psíquicas profundas e determinadas por forças invisíveis e poderosas que intentam manter o status quo (Patto, 2005). Ao reconhecer a importância da história da escola na constituição de sua identidade, o psicólogo contribui para se pensar que, da mesma forma que a realidade é construída, ela pode ser modificada pela ação coletiva da comunidade escolar.

Com base em tais reflexões e lembrando as colocações de Fresquet e Kohan (2005) de que a educação contemporânea está impregnada de conceitos esvaziados de sentido, já que são utilizados de forma indiscriminada, acabando por querer dizer tudo e, por isso mesmo, não podendo dizer nada, este trabalho visa discutir as implicações de uma experiência de incentivo à elaboração do PPP, com foco em processos de colaboração e construção conjunta. Os PPPs, anunciados pela Lei de Diretrizes e Bases da Educação Nacional (LDB - lei n 9394/1996) como obrigatórios nas escolas do país, ainda suscitam dificuldades de elaboração, sendo importante a produção de discussões que esclareçam e reflitam acerca do sentido de sua existência.

\section{O Projeto político-pedagógico como instrumento de clarificação da ação educativa}

A LDB, conforme Marçal (2001), trata da necessidade de elaboração de projetos pedagógicos segundo três eixos: flexibilidade - autonomia das escolas para realizarem seu próprio trabalho pedagógico; avaliação; e liberdade - pluralismo de ideias e de concepções pedagógicas, bem como gestão democrática do ensino público. A lei, ao prever a participação dos profissionais da educação na elaboração da proposta pedagógica e da comunidade escolar e local em conselhos escolares ou equivalentes, demonstra ênfase na proposta de gestão democrática do ensino.

O projeto pedagógico é um elemento norteador da organização do trabalho escolar. No entanto, não é apenas um conjunto de planos e projetos de professores, nem um documento que trata das diretrizes pedagógicas da instituição educativa; mas um produto específico que reflete a realidade da escola, situada em um contexto mais amplo que a influencia e é por ela influenciado. Trata-se, portanto, de um instrumento que permite clarificar a ação educativa da instituição educacional em sua totalidade, necessitando, por isso, da participação de todos os segmentos envolvidos no processo educacional (Brandão, 2003). Observa-se que as escolas que alegam possuí-los, em muitos casos, possuem 
apenas projetos pedagógicos, pretensamente desprovidos de uma origem política. Freire (1992) lembra que a prática educativa não é imparcial, envolvendo uma escolha que demonstra posturas políticas. Reconhecer tais escolhas faz que a escola não esteja a serviço da manutenção do status quo.

Um PPP, assim como pressupõe qualquer projeto, traz em si a ideia de rupturas com o presente e promessas de mudança para o futuro, mudança que passa por um período de instabilidade. Veiga (2003) diferencia dois gêneros de inovações que afetam os PPPs: regulatória e emancipatória. A primeira tem suas bases epistemológicas no caráter regulador normativo da ciência tradicional. O PPP volta-se para a burocratização da instituição educativa, tornando-a mera cumpridora de normas técnicas e mecanismos regulatórios. A segunda pressupõe uma ruptura que predisponha os indivíduos e as instituições para a indagação e a emancipação. Concentra-se no processo de construção, é a afirmação da individualidade e da particularidade da instituição educativa.

Apesar de a LDB ter sido conformada num cenário de efervescência política, de processo de redemocratização da sociedade e do aparato estatal, essa não explicita que dispositivos serão utilizados para a efetiva transformação da estrutura educacional. A autonomia pressuposta pela estrutura da LDB não deve ser confundida com descaso político nem com descompromisso do poder público, dando margem ao Estado de se eximir de suas obrigações, transferindo-as para a esfera privada e para a comunidade (Brandão, 2003).

Diante da garantia estabelecida pela LDB de participação dos profissionais de educação na elaboração desse plano pedagógico, o psicólogo apresenta-se como figura importante nessa tarefa, ao possibilitar, por exemplo, conhecimentos sobre desenvolvimento humano que auxiliam no processo de entendimento das pessoas que compõem a escola e, conseqüentemente, na adequação do projeto pedagógico a esse público.

\section{Buscando possibilidades de transformação: a elevação acima da vida cotidiana}

É importante buscar as raízes que explicam o surgimento do abismo entre a possibilidade de transformação da realidade escolar brasileira e a efetiva concretização desse processo. Um possível caminho é apontado por Heller (1989), quando analisa a estrutura da vida cotidiana e os processos de alienação na cotidianidade.

A presença da cotidianidade desde o início da vida humana, com a contribuição dos processos de manipulação e alienação social, pode fazer com que a convivência entre particularidade e generalidade se dê de forma muda e inconsciente. Consequência disso seria impossibilitar, aos indivíduos, a consciência de que lhes é possível elevar-se acima da prática cotidiana através de suas escolhas particulares, marcadas pelos juízos morais individuais, e por sua atividade humano-genérica, que lhes dá o caráter de transformadores da realidade social, gerando consequências que influenciam a própria cotidianidade (Heller, 1989).
É possível hipotetizar que a dificuldade encontrada pelas escolas para a produção dos PPPs relacione-se à alienação da vida cotidiana. Essa não permite aos indivíduos retirarem-se por alguns momentos dos sistemas em que estão profundamente imersos para lançarem sobre eles olhares críticos, visualizando-se como atores e transformadores a partir de posicionamentos políticos, característicos da atividade humano-genérica. Isso leva a questionar que tipo de proposição seria possível para modificar essa situação. Como poderia o psicólogo ingressar no ambiente escolar para contribuir junto ao grupo composto por sua comunidade no sentido de lhe permitir a tomada de consciência de suas possibilidades de elevação acima da vida cotidiana?

\section{Mediação e retomada da atividade revolucionária individual}

Diversos debates têm abordado qual deve ser a postura do psicólogo ao entrar na realidade escolar. Patto (1987) analisa historicamente tal postura e esclarece que a primeira função desempenhada por esse profissional foi a mensuração das habilidades e classificação das crianças quanto à capacidade de aprender e progredir nos estudos. Posteriormente, passa a existir uma orientação basicamente clínica, no sentido de se obterem diagnósticos e tratamentos de distúrbios. É possível observar, assim, que "o centro das explicações e das práticas psicológicas frente à queixa escolar é marcado pela visão clínica" (Souza, 1997, p. 146). A clínica na escola, como citada pelas autoras, é exercida pelo modo como o psicólogo vem desenvolvendo suas atividades, pautado na individualidade do aluno e na queixa do professor frente à falta de condições de trabalho e às deficiências e dificuldades de aprendizagem das crianças. Souza (1997) aponta necessidades de mudança na atuação do psicólogo, ressaltando, no entanto, a importância de sua presença dentro do contexto escolar, intervindo junto aos professores, aos alunos e suas famílias. Pedroza (2003) lembra que a presença desse profissional no interior da escola pode contribuir para a criação de espaços de escuta, de diálogo e reflexão, auxiliando na construção de uma escola democrática.

Levando-se em conta essas considerações, entendese que, para que o psicólogo possa atuar de forma politicamente consciente junto a comunidades escolares que, possivelmente, encontram-se em processos de alienação da vida cotidiana, não pode posicionar-se à distância ou externamente a elas. Parece lógico, ao contrário, que, inicialmente, deve colocar-se em relação próxima com essas cotidianidades, o que lhe permitirá compreender os movimentos próprios a sua dinâmica. Isso significa que não estabelecerá uma relação afastada da realidade escolar, mas interna a ela.

Newman e Holzman (2002) oferecem interessante proposta de atuação com grupos, apoiando-se na produção de Vygotsky e relacionando-a com as proposições do materialismo dialético de Marx. Essa relação é estabelecida na medida em que Vygotsky considera a atividade revolucionária como primeira e básica para o desenvolvimento do ser humano, atividade através da qual constrói a história por meio de 
uma totalidade dialética que envolve linguagem, pensamento e desenvolvimento. Os autores propõem uma intervenção que visa criar, em tempos reacionários de alienação social, zonas de desenvolvimento proximal emocionais. Defendem também que se deve tratar o que é dito não através da divisão entre interno e externo, mas como manifestação da movimentação do indivíduo entre o privado e o social.

Em muitos casos, a pré-definição social e imobilizadora do sentir pode ser geradora de conflitos, por não abarcar o privado, que acaba por não ser significado de formas únicas, características do desenvolvimento individual. Os conflitos não resolvidos, não dialogados e não mediados geram, conseguintemente, imobilismo dos indivíduos, impossibilitando-os de aprender o que é serem aprendizes e, assim, retirando-os de sua atividade revolucionária, isto é, da consciência de serem produtores de história e passarem a ser construtores de mudanças.

É possível, dessa forma, refletir sobre a possibilidade de que o psicólogo, na escola, atue com a comunidade escolar na posição de mediador, em parceria com equipe gestora e demais educadores. Esse acolheria os conflitos surgidos no grupo, auxiliando a significá-los, permitindo construir com o outro, e não por ele, formas únicas de internalização da emocionalidade, produzindo, assim, o desenvolvimento conduzido pela aprendizagem. Estabelecer-se-ia a relação entre social e privado que é promotora do desenvolvimento através da mediação do outro, bem como a explicitação da relação entre a particularidade e a produção humano-genérica, reduzindo-se a alienação da vida cotidiana. Indivíduos emocionalmente desenvolvidos estariam novamente habilitados ao engajamento na atividade revolucionária, na produção de História, na ação autônoma e criativa. Esse engajamento faz-se necessário à elaboração do PPP, que pressupõe o reconhecimento da identidade escolar construída socialmente e passível de transformação.

Considerando tais reflexões, o presente trabalho discute uma experiência de colaboração e incentivo à elaboração do PPP em uma escola pública para séries iniciais do Ensino Fundamental de Brasília - DF. A proposta surgiu a partir da compreensão da necessidade de iniciativas que buscassem compatibilizar a abstração da previsão legal com a realidade escolar, em que nem sempre existe a possibilidade de exercício da autonomia. Além disso, abre-se espaço para a discussão referente às posturas que o psicólogo deve adotar no contexto escolar, fugindo de intervenções autoritárias baseadas no poder de especialista a serviço da normalização. Propõe, ao contrário, que esse profissional possa imergir na cotidianidade dos indivíduos com os quais se relaciona, servindo-lhes de mediador, impulsionando-lhes o desenvolvimento e levando-os a refletir acerca de seus papéis como agentes históricos.

\section{Método}

O presente trabalho foi desenvolvido junto a uma Escola Pública para séries iniciais de Brasília - DF, tendo, por foco principal, a atuação do psicólogo junto a seu corpo pedagógico'. A intervenção foi conduzida por uma das autoras, na qualidade de estágio acadêmico supervisionado pela outra. A escola escolhida já havia participado de outras iniciativas junto à Universidade, tendo manifestado o interesse em discutir a formulação do PPP. Realizaram-se reuniões semanais, no período vespertino, com a equipe pedagógica, membros da coordenação e direção da escola com duração variando entre uma e três horas. O horário dos encontros coincidia com aquele reservado às reuniões pedagógicas semanais dos professores, dirigidas pela coordenadora. Foi feito o convite para participação de uma funcionária do corpo administrativo, mas esse somente foi aceito em uma ocasião. Utilizou-se a observação participante, objetivandose a mediação e a facilitação do debate. As intervenções apoiaram-se na concepção de que o psicólogo deve atuar de forma crítica e politicamente consciente. Essa postura implica um cuidado para que seu trabalho não reflita e perpetue as ideologias de hierarquização e dominação presentes na figura do especialista que possui conhecimento neutramente produzido, podendo utilizá-lo para o diagnóstico e tratamento dos indivíduos e das instituições para seu ajustamento ao sistema normatizador.

Procurou-se trabalhar com os conteúdos trazidos pela equipe pedagógica, ressaltando que esses se inscrevem em um longo processo histórico de construção das identidades individuais e da própria escola. Esse processo é marcado por relações de autoridade e por forças de interesses políticos de manutenção do status quo com que todos contribuem de variadas maneiras. Demonstrando que a realidade e a identidade escolar são historicamente construídas por todos, buscou-se ainda despertar a ideia de que a realidade construída pode também ser modificada pela atuação coletiva.

Após cada reunião, as observações suscitadas eram registradas, sendo posteriormente discutidas e analisadas pelas autoras. Esse processo auxiliou a constituir subsídios para as decisões relativas ao andamento do trabalho, estabelecendo-se um processo de contínua reflexão acerca da dinâmica do grupo de discussão.

No primeiro contato com a equipe pedagógica, foram apresentados os objetivos do projeto de incentivo à elaboração do PPP como um todo, quais sejam: discutir a importância da elaboração do PPP com os profissionais da educação e com a comunidade escolar; incentivar a análise da realidade da escola, a fim de estabelecer sua identidade; fomentar a elaboração de metas para escola, bem como sua função e finalidade; auxiliar na elaboração do PPP, considerando a identidade da escola e contendo os meios necessários ao alcance das metas propostas; planejar com a escola um cronograma de implantação do PPP; acompanhar periodicamente a inserção do PPP na prática cotidiana da escola; rever com a escola a adequação do PPP às novas realidades que venham a surgir ao longo do tempo. Mediante essa apresentação inicial, buscou-se fornecer, à equipe pedagógica,

$1 \mathrm{Na}$ atuação junto à escola, além das autoras, participou ainda um estagiário, que atuou em alguns encontros com a equipe pedagógica. 
a compreensão do alcance da proposta de trabalho trazida. Contudo, a ênfase não foi dada à consecução dos objetivos em si mesma, mas à consolidação de um processo que permitisse o reconhecimento da possibilidade de autonomia na construção do PPP pela comunidade escolar.

\section{Resultados e discussões}

\section{Desconstrução da autoridade do psicólogo e exploração do conceito e do processo de elaboração do Projeto político-pedagógico}

O primeiro contato com a equipe pedagógica revelou uma expectativa de que fosse trazida uma proposta pronta de PPP que apenas seria adaptada à escola. Essa expectativa suscitou a percepção de que a figura do psicólogo escolar estava investida de um caráter de autoridade, bem como de que a equipe pedagógica colocava-se em posição de receptora de conhecimentos. Procurando afastar tal percepção, discutiu-se acerca do que aqueles profissionais entendiam por definição de PPP e como estavam os debates a esse respeito na Instituição. Ao final do encontro, foram colocados os objetivos gerais do trabalho que originou a proposta de intervenção, demonstrando-se, com essa postura, que nada pronto seria apresentado.

Observou-se que as representações das profissionais acerca do PPP são bem próximas àquelas encontradas na literatura. Esse foi descrito como demonstrativo da identidade da escola e percebido como de suma importância, por permitir que cada profissional pudesse se identificar individualmente com o trabalho institucional, bem como caracterizá-lo diante do público externo à escola. A definição foi reforçada na mediação do debate, apontando-se o contexto de surgimento do PPP na LDB, envolvendo-o em três eixos: flexibilidade; necessidade de avaliação constante; e liberdade, pluralismo de ideias e concepções pedagógicas.

Demonstrando que a proposta de trabalho constituíase primordialmente em uma abertura de espaço para a escuta da escola, propôs-se o início das discussões, pedindo-se que a equipe pedagógica relatasse como os debates acerca do PPP estavam ocorrendo na Instituição. A equipe apontou uma série de dificuldades tencionando justificar a inexistência do PPP até aquele momento. As principais questões apontadas foram: a rotina corrida da escola, abrangendo assuntos de maior prioridade; o fato de o quorum presente nas reuniões acerca do tópico raramente contar com todos os profissionais; a percepção de que parecia que o PPP estaria sendo retirado do vazio, isto é, não haveria bases para sua constituição; e a percepção de que não havia, por parte da escola, um conhecimento aprofundado de sua clientela, o que não permitia a formulação de ações que visassem atingila beneficamente.

Delineou-se, após esses relatos, um movimento que se mostraria comum na dinâmica grupal até o término dos trabalhos. Sempre que eram apontadas inúmeras dificuldades (após a abertura de um espaço de escuta e acolhimento da angústia provocada por elas), surgiam relatos de experiências vividas pelos profissionais em outros contextos de trabalho ou mesmo na própria escola, que auxiliavam a delinear caminhos para responder às dificuldades apresentadas. Assim é que, diante da exposição dos motivos pelos quais o PPP ainda não havia sido constituído, surgiu um relato de uma das professoras sobre como este havia sido elaborado em uma outra escola onde havia trabalhado. O relato infundiu na equipe a percepção de que não se tratava de ação impossível e a primeira contribuição obtida foi a de que, para que todos participem do movimento de elaboração do PPP, não se faz necessário que estejam presentes em todas as reuniões de discussão. Bastaria que houvesse um constante movimento de circulação de informações e um acordo de que todos poderiam ter espaço para se pronunciar em qualquer momento do processo. Assim, ao não condicionar a elaboração do PPP à presença de toda equipe pedagógica, uma primeira amarra que impedia o trabalho pôde ser relativizada. A primeira prática a ser proposta foi a adoção de uma caixa de sugestões, que ficaria à disposição de quem a quisesse utilizar quando não pudesse estar presente nos trabalhos de discussão. Em encontro posterior, surgiu, de uma das professoras, a ideia de que cada uma das pessoas presentes se comprometesse a "adotar uma colega" para o relato do que havia sido discutido. Interessante observar que essa segunda ideia, partindo da própria equipe, surtiu maiores efeitos do que a primeira, que havia sido proposta pelas psicólogas.

Ainda a partir das primeiras dificuldades apontadas, dois eixos temáticos importantes surgiram e foram foco do trabalho posterior durante a maioria dos encontros. O primeiro referia-se à necessidade de um resgate histórico da escola (já com 30 anos de funcionamento), o que permitiria o delineamento de sua identidade, passo essencial na formulação do PPP. Essa necessidade foi detectada nas falas de que parecia que o PPP precisava ser retirado do vazio. O segundo dizia respeito ao anseio dos profissionais por conhecimento mais abrangente acerca da clientela atendida pela escola. As psicólogas apontaram, ainda, que a discussão acerca do PPP, idealmente, deve envolver toda a comunidade escolar (equipe pedagógica, pais, alunos, servidores e demais interessados). Assim, as sugestões que passariam a ser levantadas a partir desse primeiro encontro envolveriam o levantamento histórico acerca da escola, formas de conhecer e responder às questões referentes à clientela e às formas de incluir a comunidade escolar como um todo na discussão acerca do PPP.

\section{Questões acerca da clientela: espaço de escuta e elaboração}

Com relação à clientela, os primeiros movimentos do grupo revelaram-se em manifestações de descontentamento e frustração quanto à postura dos pais e famílias diante da escola e do trabalho individual de cada profissional. Houve queixas quanto à não valorização da escola pública, não participação dos pais nas atividades realizadas pela escola e não colaboração desses com as propostas das professoras 
(cobrança de deveres de casa e comparecimento em reuniões). Acolhendo as queixas e legitimando-as, procurou-se demonstrar que é preciso compreender as raízes de tais comportamentos e atitudes das famílias, verificando de que contexto educacional elas provêm e o que entendem por posturas participativas. Demonstrou-se que tal construção histórica seria relevante por poder apontar que o que para as profissionais parece óbvio não necessariamente o é para as pessoas com as quais trabalham. Foi possível inferir, ainda, pelos relatos da equipe, que há um certo grau de não identificação das profissionais com o próprio trabalho, o que pode ser gerador de intenso sofrimento e angústia. Ao mesmo tempo que manifestavam não perceber valorização dos pais perante a escola pública, não confiavam seus próprios filhos a ela e, ao não sentirem valorizado seu próprio trabaIho, também acabavam por não confiar nele ou, ainda, por não confiar naquele que é desenvolvido pelos colegas. Das próprias queixas, passaram a emergir sugestões e posições pró-ativas em relação ao tema. Foram relembrados eventos realizados na escola que contaram com a presença e interesse maciços das famílias e iniciou-se a busca por maneiras de repetir essas ocasiões e torná-las movimento permanente de aproximação entre a escola e sua clientela. A iniciativa que foi acolhida e posta em prática ao longo do semestre foi a de utilizar a reunião de pais para se iniciar movimento de exposição das questões que inquietavam a equipe acerca da clientela, bem como para começar sua inclusão na discussão acerca do PPP.

Foram realizados vários debates acerca de formatos de coletas de dados referentes à clientela: questionários fechados, já utilizados no início de cada ano letivo para coleta de dados sociodemográficos (importantes em termos quantitativos); e questionários abertos e subjetivos, que poderiam parecer proporcionar dados qualitativamente mais profundos, mas demonstraram não permitir essa conclusão de forma imediata, analisando-se seus efeitos ao longo da história da escola. Assim, apareceram como formas de sondagem inicial que, entretanto, não permitiam um aprofundamento qualitativo das concepções apontadas pelos pais. Isso se caracterizava por não possuírem retorno significativo, já que a pequena quantidade de questionários que retornava trazia respostas curtas e pouco profundas.

Aimportância da aproximação pessoal com as famílias foi aos poucos ficando patente. As reuniões gerais de pais e conversas com as professoras demonstraram ser momentos profícuos para estreitamento de relações da escola com sua clientela, permitindo que essa fosse conhecida de forma gradativa e natural. Foi também aparecendo que quaisquer eventos realizados pela escola, tais como os suscitados por datas comemorativas ou demonstrações culturais, e que contassem com a presença das famílias, seriam sempre importantes espaços de compartilhamento de experiências e acolhimento de demandas da clientela.

Dessa forma, a reunião de pais foi idealizada pela própria equipe, tencionando que fosse um primeiro passo para a resposta a seus anseios. Foi elaborado questionário fechado com espaço para justificativas e, ao mesmo tempo, foi previsto um espaço de discussão aberta durante a reunião que, em um segundo momento, foi aprofundada em pequenos grupos relativos a cada série. A equipe produziu ainda uma dramatização, que introduziu a reunião, demonstrando tanto as relações entre pais e filhos frente à escola, quanto o esforço da equipe para aproximar as famílias da instituição.

Foi interessante observar que, nessas discussões, os debates não ficaram restritos aos horários marcados com as psicólogas. Ao contrário, estendiam-se em outras ocasiões do cotidiano escolar. Essa tendência ficou clara quando as professoras traziam produções e sugestões elaboradas ao longo da semana para serem discutidas pelo grupo. Apareceu ainda quando foi previsto que os últimos preparativos para a reunião, como fechamento da estrutura do questionário, delineamento da dinâmica de discussão e ensaio da dramatização, seriam feitos em outro horário, de forma independente.

A avaliação da equipe acerca dos resultados obtidos por meio da reunião de pais foi positiva, considerando-se que representou um primeiro e importante passo na aproximação que desejava empreender com a clientela. Serviu para que avaliasse algumas posturas que deram certo e outras que precisarão ser melhoradas em ocasiões posteriores. Observouse que as participações foram significativas, tanto no grande quanto nos pequenos grupos. Os pais foram convidados a continuarem suas manifestações, escrevendo em mural colocado na entrada da escola. Além disso, foram convidados a participar dos encontros de discussão acerca do PPP, o que, entretanto, não ocorreu até o término deste trabalho.

\section{O resgate histórico no reconhecimento da identidade escolar}

Quanto ao eixo temático do resgate histórico da escola para delineamento de sua identidade, constatou-se que havia alguns pais e professoras que foram alunos da escola e que poderiam auxiliar no levantamento de dados. Contudo, não houve sugestões acerca dos procedimentos concretos a serem adotados. Houve também a lembrança de que, na comemoração do aniversário de 29 anos da escola, contou-se com a presença de seis ex-diretores e foi realizada uma exposição de fotos. Foi apresentado um documento contendo o histórico formal da instituição. Nesse, havia um amontoado de datas e dados estatísticos sobre quantos alunos eram atendidos e quantas turmas havia de cada série (com uma lacuna de cerca de 20 anos nas informações). A partir do documento, foi ressaltada a concepção de que o histórico da instituição, para refletir sua identidade, necessita possuir um caráter vivencial e concreto, não apenas factual e estatístico.

Com base na percepção de que pode ser imobilizador conferir autonomia a quem não a possui em sua história, foram propostas à equipe algumas questões para nortear a reflexão. Levantaram-se perguntas tais como: nesses 30 anos de escola, já houve um Projeto Político-Pedagógico? Quantos diretores passaram pela escola, quanto tempo permaneceram e como foi sua entrada (eleição, indicação ou 
imposição da Secretaria de Educação)? O que caracterizou cada gestão? Durante esses anos, mudou o perfil dos professores da escola (de onde vinham, por quais motivos)? Mudou o perfil dos servidores da escola? Mudou o perfil da clientela? Nesses 30 anos, quais foram os projetos iniciados pela escola que deram certo e que continuam vigorando até hoje, mesmo que com outra feição? Quais os que deram certo, mas não vingaram (por quê)? Quais os que deram errado?

As questões produziram algumas iniciativas voluntárias de ações para respondê-las, tais como: procurar documentação acerca das gestões dos diretores e entrevistar ex-aluno conhecido para saber com o que poderia contribuir. Houve também espaço para que fosse debatida a relevância dessas questões e sua abrangência.

Conseguiu-se uma lista de ex-diretores, seus contatos e tempo de gestão. Sugeriu-se que cada profissional ficasse responsável por realizar uma entrevista com uma dessas pessoas. Houve debates acerca do formato de tais entrevistas (pessoalmente ou via eletrônica). As psicólogas auxiliaram a pontuar vantagens e desvantagens de cada formato, decidindo a equipe que isso dependeria da disponibilidade de cada entrevistado e dos aprofundamentos a serem buscados após o primeiro contato.

\section{A demanda do grupo por novas iniciativas}

Por demanda da própria equipe pedagógica, foi resolvido que era momento de se passar ao próximo passo na elaboração do PPP: o levantamento de problemas e anseios atuais da escola para posterior elaboração de metas a serem atingidas futuramente. Foi ressaltado que se poderia começar essa etapa, lembrando-se que as anteriores jamais estariam totalmente fechadas, necessitando sempre serem revistas e aprimoradas. A equipe relembrou, então, iniciativa realizada no início do ano letivo, em que, em pequenos grupos, levantaram-se problemas atuais da escola. Propôs-se o resgate dessas questões e, se não mais fossem encontradas ou não fossem mais atuais, novas questões seriam elaboradas.

No último encontro realizado, ocorreu intensa discussão e debate sobre questões trazidas pela própria equipe. Foram elaborados projetos e formas para suprir tais questões levantadas e discutidas e foi previsto espaço para que voltassem a ser revistas no próximo ano letivo, não se deixando para trás o que havia sido conseguido até ali.

\section{Inserção da comunidade na elaboração do PPP: relações de poder e hierarquização}

Cabem ainda algumas observações quanto à inserção da comunidade escolar na discussão acerca do PPP, mais especificamente em relação à inclusão dos servidores da escola do corpo administrativo. Foi interessante constatar que, nas observações da equipe pedagógica acerca das dificuldades quanto à inclusão desse público, estava implícita uma separação histórica em termos de hierarquia e autoridade. Assim é que foi dito que era bastante difícil reunir esses servidores, que eles não se interessavam em opinar sobre tais questões nem gostavam de fazê-lo, que não tinham tempo de participar das discussões por trabalharem apenas seis horas, que eram, em sua maioria, desconhecidos dos próprios alunos.

Em duas oportunidades, houve o convite para que uma funcionária participasse da reunião. Na primeira, essa se encontrava na sala, fazendo outras atividades e se recusou a sentar-se mais próximo, dizendo que, se fosse preciso que ela respondesse a alguma questão, poderiam perguntar, pois ela estava ouvindo. Na segunda, essa mesma funcionária acabou sentando-se no círculo de discussão por alguns minutos, não dizendo coisa alguma e retirando-se logo em seguida. Sugeriu-se que se aproveitasse a reunião de pais para reunir também os servidores, mas a ideia, embora aparentemente bem acolhida, não foi realizada.

\section{A concretização de primeiros passos}

Considera-se que o espaço oferecido foi bastante benéfico para a equipe pedagógica. Inicialmente, cabe apontar que se criou um espaço institucionalmente reconhecido de discussão permanente acerca do PPP, algo que no início foi tratado como impossível, diante das outras prioridades da pauta escolar. Além disso, houve considerável aumento da participação dos integrantes do grupo na discussão. Esses passaram a expor mais suas opiniões, mesmo quando discordantes, a sugerir e idealizar ações que tiveram oportunidade de colocar em prática, e dispensaram tempo para as atividades relativas ao PPP fora dos horários previstos das reuniões com as psicólogas.

Dessa forma, foi possível enfatizar, junto ao grupo, que, embora o PPP não estivesse concluído, o processo iniciado serviria de base para que a equipe conseguisse sentir-se segura na autonomia de que dispõe para sua elaboração.

\section{Considerações finais}

O trabalho realizado permitiu observar que as falas das profissionais da comunidade escolar vão ao encontro das ideias propostas por Heller (1989), em relação à alienação da vida cotidiana, e por Newman e Holzman (2002), no tocante aos conflitos gerados pelo distanciamento da mediação social auxiliando a significar e desenvolver a emocionalidade no âmbito privado. Observe-se que, por intermédio da fala e da mediação fornecida pelas psicólogas, puderam ser explicitadas as amarras cotidianas que pareciam imobilizar a equipe na construção do PPP, quais sejam: falta de tempo para reuniões; dificuldades devido à não participação de todos; sentimentos de indignação e frustração perante as posturas da clientela atendida pela escola; impossibilidade de iniciativas que permitissem um resgate histórico e consequente percepção da identidade do trabalho escolar peculiar àquela realidade específica; profundos conflitos que deixavam implícita uma não identificação com o próprio trabalho e com o dos colegas; distanciamento histórico mantido ideologica- 
mente em relação aos funcionários da escola que também constituem a comunidade escolar.

A atividade de expressão dessas amarras e conflitos representa um momento de elevação do grupo acima da prática inconsciente da vida cotidiana. Isso permite a manifestação das particularidades individuais e a construção de possibilidades de ação transformadoras que alteram a própria cotidianidade, como observado nas sugestões e ações realizadas pelo grupo, ficando explícita aí a atividade humano-genérica (Heller, 1989). Já se considerando as palavras de Newman e Holzman (2002), tais iniciativas poderiam representar um retorno à atividade revolucionária, já que a atividade de mediação permitiu a construção de formas de sentir únicas e individuais, a partir do compartilhado socialmente, o que se coaduna com a concepção da aprendizagem conduzindo o desenvolvimento.

Quando Vygotsky (1984) postula o conceito de zona de desenvolvimento proximal, fala em níveis de desenvolvimento. Afasta-se de uma concepção de desenvolvimento por etapas ou estruturas estanques e sucessivas. Introduz a concepção de que o desenvolvimento dá-se com o outro, isto é, a mediação do outro permite que o que foi aprendido inicialmente no social possa ser internalizado de formas únicas. Newman \& Holzman (2002) lembram que esse processo é também verdadeiro para a emocionalidade. Wallon (1975) aponta que a linguagem surge para simbolizar a ação e os objetos. Entretanto, embora atue nessa transição, não consegue abarcar a totalidade dos fatos. Em relação à emocionalidade, acaba por racionalizá-la. No entanto, a emocionalidade pura não desaparece sob o jugo da linguagem racional, continuando a ser impulsora da ação e ainda podendo provocar o aparecimento de conflitos, já que não é completamente significada ou consciente na fala.

É possível entender-se, a partir daí, que o psicólogo na escola pode possuir um papel de mediação, em que não sobrepõe seus conhecimentos de autoridade científica ao outro, mas se permite estar com o outro na vivência e análise dos conflitos, levando-o a desenvolver formas próprias de internalização da emocionalidade.

Wallon (1975) ressalta ainda que o individualismo burguês, calcado no positivismo e no existencialismo, relega o indivíduo a um isolamento impotente, isto é, retira-o dos sistemas em que atua, dando-lhe a impressão de que não repercute neles de nenhuma maneira. Isso também pôde ser observado na fala das profissionais que, caricaturalmente, poderia ser expressa da seguinte forma: "Nós queríamos construir o PPP, resgatar a história, participar, mudar as condições da escola, mas a Secretaria de Educação, os pais, o governo, a escola pública não permitem a ação". Em outras palavras, todos esses sistemas aparecem nas falas como entidades autônomas, não havendo a percepção de que as profissionais os compõem e os constroem. Dessa forma, a intervenção do psicólogo no grupo escolar teria também a finalidade de identificar, junto aos indivíduos, os aspectos de seu cotidiano, tornando-os conscientes e permitindo o surgimento de novas formas de ação.
Quando as teorizações e discussões da Psicologia Escolar atêm-se à consideração da clínica como forma de diagnóstico e intervenção dos indivíduos e grupos calcada em uma oposição entre interno e externo, chega-se à conclusão de que o profissional deveria manter-se fora do ambiente escolar. Isto é, o psicólogo não deveria imergir no cotidiano escolar para que não se investisse de suas peculiaridades, o que prejudicaria sua interpretação dos conteúdos ali gerados. Decorre dessa concepção que tais conteúdos, expressos pela linguagem, representariam a realidade interna dessas comunidades em sua totalidade e não apenas uma construção dialética da complexidade.

Um modelo de intervenção distanciado do cotidiano pode permitir aos psicólogos atenderem a um número consideravelmente grande de demandas, já que não se aproximam de forma profunda de qualquer das realidades estudadas. Questiona-se, entretanto, com que profundidade a atuação dos profissionais, nesse modelo, chega às escolas e quais os reais e duráveis ganhos gerados para os indivíduos envolvidos.

Entende-se que a imersão do profissional da Psicologia na escola, de forma profunda, permitindo-lhe experimentar a cotidianidade vivida pelos membros da comunidade escolar e exercer papel de mediador que propicie o desenvolvimento individual e grupal, parece ser uma ação que é politicamente consciente. Tal intervenção pode permitir superar um modelo de autoridade de saberes, em que se estabelecem relações de poder entre as ciências, como a Psicologia e a Pedagogia, tornando alguns profissionais dependentes da intervenção de outros e inconscientes de suas possibilidades de autonomia e produção histórica. A desconstrução dessas ideologias é essencial, já que propostas de transformação da realidade, seja no âmbito educacional ou em qualquer outro, somente são possíveis se os indivíduos se perceberem como partes integrantes e ativas em seus sistemas de ação cotidiana, o que somente ocorrerá se lhes forem garantidas as condições necessárias a seu desenvolvimento.

\section{Referências}

Bobbio, N., Matteucci, N., \& Pasquino, G. (1992). Dicionário de Politica (4a ed.) (C. C. Variale, Trad.). Brasília: EDUnB.

Brandão, C. P. (2003). Projetos Político-pedagógicos e a Qualidade da Educação: a Visão dos seus autores. Dissertação de mestrado, Faculdade de Educação, Universidade de Brasília, Brasília.

Chauí, M. (1994). O que é Ideologia (37a ed.). Coleção Primeiros Passos. São Paulo: Editora Brasiliense.

Freire, P. (1992). Pedagogia da Esperança: um reencontro com a Pedagogia do oprimido (12a ed). Rio de Janeiro: Paz e Terra.

Freire, P. (2001). Pedagogia dos Sonhos Possíveis. São Paulo: Editora Unesp. 
Fresquet, A. M., \& Kohan,W., (2005). Educação, Sociedade e Cidadania. Brasília/São Paulo: EDUnB/Moderna.

Heller, A. (1989). Cotidiano e história. Rio de Janeiro: Paz \& Terra

Marçal, J. C. (2001). Progestão: como promover a construção coletiva do projeto pedagógico da escola?. Módulo III. Brasília: CONSED Conselho Nacional de Secretários de Educação.

Newman, F., \& Holzman, L. (2002). Lev Vygotsky cientista revolucionário. São Paulo: Loyola.

Patto, M. H. S. (1987). Psicologia e ideologia: uma introdução crítica à psicologia escolar. São Paulo: Ed. T. A. Queiroz.

Patto, M. H. S. (2005). Exercícios de Indignação: Escritos de Educação e Psicologia._São Paulo: Casa do Psicólogo.

Pedroza, R. L. S. (2003). A Psicologia na formação do professor: uma pesquisa sobre o desenvolvimento pessoal de professores do ensino fundamental. Tese de doutorado, Universidade de Brasília, Brasília.
Souza, M. P. R. de S. (1997). As contribuições dos estudos etnográficos na compreensão do fracasso escolar no Brasil. Em A. M. Machado \& M. P. R. de S. (Orgs.), Psicologia escolar: em busca de novos rumos (pp. 139-156). São Paulo: Casa do Psicólogo.

Veiga, I. P. A. (2003). Inovações e projeto-pedagógico: uma relação regulatória ou emancipatória?. Caderno Cedes, 23(61), 267-281.

Vygotsky, L. S. (1984). A Formação Social da Mente. São Paulo: Martins Fontes.

Wallon, H. (1975). Objectivos e Métodos da Psicologia. Lisboa: Editorial Estampa.
Recebido em: 05/10/2009

Reformulado em: 19/05/2010

Aprovado em: 01/06/2010

\section{Sobre as autoras}

Aline Wanderer (wanderer_aline@yahoo.com.br)

Psicóloga do Tribunal de Justiça do Distrito Federal e Territórios, Brasília - DF

Regina Lucia Sucupira Pedroza (rpedroza@unb.br)

Instituto de Psicologia da Universidade de Brasília, Brasília - DF

\section{Correspondência}

Aline Wanderer

SHIS QI 3 Conjunto 5 Casa 8 - Bairro Lago Sul - 71605-250 Brasília - DF 